\title{
Comparison between Laparoscopic Hysterectomy and Abdominal Hysterectomy
}

\author{
Shrestha R, ${ }^{1}$ Yu LH ${ }^{2}$ \\ ${ }^{1}$ Department of Obstetrics and Gynaecology, Kathmandu Model Hospital, ${ }^{2}$ Third Affiliated Hospital, Zhengzhou Univer- \\ sity, Zhengzhou, PR China.
}

\begin{abstract}
Aims: Hysterectomy can be performed by abdominal, vaginal and laparoscopic methods. Laparoscopic hysterectomy has been reported as an alternative to traditional abdominal hysterectomy with benefit of early recovery, short hospital stay and less operative complications. This study compared laparoscopic versus abdominal hysterectomy in terms of surgery time, blood loss, post-operative recovery, and duration of hospital stay.
\end{abstract}

Methods: This is a retrospective comparative study among sixty patients who underwent laparoscopic or abdominal hysterectomy for various indications in the Department of Obstetrics and Gynaecology of the Third affiliated hospital of Zhengzhou University from January to March 2007. The data of the patients meeting the set criteria were obtained from the hospital records and hospital based computerized coding system. Enrolled cases were divided in two groups with thirty in each arm. Group TLH (total laparoscopic hysterectomy) was designated for patients who underwent total laparoscopic hysterectomy and group TAH (total abdominal hysterectomy) for those who underwent total abdominal hysterectomy.

Results: There was comparatively less blood loss in TLH group $(60.2 \pm 5.17 \mathrm{ml}$ versus $75.7 \pm 7.12 \mathrm{ml})$ but it was statistically insignificant $(\mathrm{p}=0.12)$. The laparoscopic hysterectomy took longer time $(107.6 \pm 32.4 \mathrm{~min}$ versus $74.9 \pm 31.1 \mathrm{~min})$ than the abdominal $(\mathrm{p}<0.001)$. There was early recovery among TLH group $1.6 \pm 0.6$ days versus $2.1 \pm 0.5$ days in TAH group $(\mathrm{p}=0.001)$. Mean duration of hospital stay was significantly shorter in TLH group 7.6 \pm 1.9 days versus $10.1 \pm 2.1$ days in TAH group $(\mathrm{p}<0.001)$

Conclusions: Laparoscopic hyserectomy is an effective alternative to abdominal hysterectomy with the advantage of less intra-operative blood loss, fast recovery and short hospital stay.

Keywords: abdominal hysterectomy, hospital stay, laparoscopic surgery.

\section{INTRODUCTION}

Hysterectomy is one of the most common surgical procedures. ${ }^{1-3}$ Hysterectomy can be performed by abdominal, vaginal and laparoscopic method. Most common reasons for performing hysterectomies are malignancies, fibroids, bleeding irregularities, endometrial hyperplasia, cervical dysplasia, endometriosis and genital prolapse. ${ }^{4-6}$ Abdominal hysterectomy has been the most popular method but it is more invasive and is associated with more blood loss, delayed in recovery and longer hospital stay. First reports on laparoscopy within the female pelvis was made by Roul Palmer in Paris in 1944. ${ }^{4,5}$ From this, it was a small step towards laparoscopically assisted vaginal hysterectomy (LAVH) and finally total

\section{CORRESPONDENCE}

Dr Ranjana Shrestha

Department of Obstetrics and Gynaecology

Kathmandu Model Hospital, Exhibition Road, Kathmandu

Email: ranjana_514@hotmail.com

Phone: +977-9841817268 laparoscopic hysterectomy (TLH) was established from 1989 onwards. ${ }^{5,8}$ Till now, several studies have confirmed the feasibility of TLH as a safe method with better post-operative recovery, reduced need of analgesics and shorter hospital stay. ${ }^{9-11}$ With further developments in techniques and experience, more complicated operations like radical hysterectomies and lymphadenectomies are being performed laparoscopically nowadays. ${ }^{3,8,12}$ The purpose of this study was to compare total laparoscopic versus total abdominal hysterectomy in terms of surgery time, total blood loss, post-operative recovery and duration of hospital stay.

\section{METHODS}

This is a retrospective comparative study done among sixty patients who underwent total laparoscopic or total abdominal hysterectomy for various indications in the Department of Obstetrics and Gynaecology of the Third affiliated Hospital of Zhengzhou University from January to March 2007. The data 
of the patients were obtained from hospital records as well as hospital based computerized coding system. Case selection was on the basis age, size of the uterus and disease condition. Women of age 35-60, having benign disease with uterus size of less than 12 weeks were included in the study. Enrolled patients were grouped into two of thirty each. Group TLH was designated for patients who underwent total laparoscopic hysterectomy and group TAH for those who underwent total abdominal hysterectomy. Different variables of each patient were recorded. Data were gathered with help of Microsoft Excel and analyzed with software SPSS 13 and PHSTAT 2. Independent t-test was used for comparisons of different numeric variables such as age, blood loss, hospital stays. Likewise z-test was used to compare the percentage of certain characteristics such as blood loss $<50 \mathrm{ml}$. Statistical significance was defined as $\mathrm{p}<0.05$.

\section{RESULTS}

Sixty patients who underwent TLH or TAH for various indications were enrolled for the study. The mean age of the patients in TLH group was $42.2 \pm 5.4$ years and that of TAH group was $44.6 \pm 6.4$ years $(p=0.13)$. The indications for surgery were: fibroids 32 (53.3\%), adenomyosis $12(20 \%)$, DUB 8 (13.3\%), PID $5(8.3 \%)$, endometriosis 2 (3.3\%) and CIN III $1(1.7 \%)$.

\section{Surgery Time}

The surgery time for TLH ranged from 60 to 180 minutes, where as it ranged from 30 to 150 minutes for TAH. So the mean surgery time was longer for TLH when compared to TAH, which was statistically significant $(\mathrm{p}<0.001)\{$ Table 1$\}$.

Table 1. Mean surgical time taken in TAH and TLH $\operatorname{groups}(\mathrm{n}=60)$.

\begin{tabular}{ll}
\hline Groups & $\begin{array}{l}\text { Surgical time in minute } \\
(\text { Mean } \pm \text { SD })\end{array}$ \\
\hline TAH $(n=30)$ & $74.9 \pm 31.1$ \\
TLH $(n=30)$ & $107.6 \pm 32.5$ \\
\hline
\end{tabular}

\section{Blood loss}

The over all intraoperative blood loss was less in TLH when compared to TAH but it was not statistically significant. Majority of cases $28(93.3 \%)$ cases in
TLH versus 19 (63.3\%) in TAH had blood loss of less than $100 \mathrm{ml}$. Where as $2(6.6 \%)$ cases in TLH group and $11(36.7 \%)$ in TAH group had blood loss of more than $100 \mathrm{ml}$ (Table 2).

Table 2. Mean blood loss $(n=60)$.

\begin{tabular}{ll}
\hline Groups & $\begin{array}{l}\text { Blood loss } \\
(\text { Mean } \pm \text { SD) }\end{array}$ \\
\hline TAH $(\mathrm{n}=30)$ & $75.7 \pm 7.12 \mathrm{ml}$ \\
TLH $(\mathrm{n}=30)$ & $60.2 \pm 5.17 \mathrm{ml}$ \\
\hline
\end{tabular}

$\mathrm{p}=0.12$

\section{Day of mobilization}

The study showed that post-operative mobilization and recovery was significanntly earlier in patients among TLH group when compared to TAH group. The mean day for mobilization in TLH group was $1.6 \pm 0.6$ days versus $2.1 \pm 0.5$ days in TAH group $(p=0.001)$.

\section{Hospital stay}

The mean duration of hospital stay for patients in TLH group was significantly shorter when compared to TAH group ( $7.6 \pm 1.9$ versus $10.1 \pm 2.1$ days $)$ which was statistically significant $(\mathrm{p}<0.001)$.

\section{DISCUSSION}

In this study there is homogeneity among demographic character in regards to their age and indication for surgery. The mean age of the patients in TLH group was 42.2 years versus 44.6 years in TAH group. The most common indications for surgery were fibroids 32 (53.3\%), adenomyosis 12 (20\%), DUB 8 (13.3\%), PID 5 (8.3\%), endometriosis 2 (3.3\%) and CIN III 1 $(1.7 \%)$. Similar findings were obtained in the study of Loh et al. ${ }^{13}$ in which the most common indication for surgery were fibroids contributing 48 (60\%), and adenomyosis $21(26 \%)$ which is comparable to the present study.

In the present study the mean surgical time taken for laparoscopic hysterectomy was longer when compared to abdominal hysterectomy (107.6 \pm 32.4 min versus $74.9 \pm 31.1 \mathrm{~min}$ ), which was statistically significant $(\mathrm{p}<0.001)$. Similar finding was shown in the studies by Garry et $\mathrm{al}^{4}$ and Michel et al, ${ }^{8}$ stating that laparoscopic hysterectomy takes longer. Likewise in a study by Loh et $\mathrm{al}^{13}$, the mean duration 
of surgery was shown as 159 minute in TLH group and 98 minute in TAH group.

The mean intra-operative blood loss in the current study was less in laparoscopic hysterectomy $(60.2 \pm 5.17 \mathrm{ml}$ versus $75.7 \pm 7.12 \mathrm{ml})$ but it was statistically not significant $(\mathrm{p}=0.12)$. Similar findings were present in the study by Perino et $\mathrm{al}^{12}$ as well as in study by Katherine et $\mathrm{al}^{14}$ in which the blood loss was $138 \mathrm{ml}$ in TLH when compared to $504 \mathrm{ml}$ in TAH $(\mathrm{p}<0.001)$. In our study, it was shown that the patients who underwent laparoscopic hysterectomy were mobilized earlier than those who underwent abdominal hysterectomy. The mean time of postoperative mobilization was $1.6 \pm 0.6$ days for $\mathrm{TLH}$ group and $2.1 \pm 0.5$ days for TAH group that was statistically significant $(\mathrm{p}=0.001)$. Similar result was obtained in the study of Loh et $\mathrm{al}^{13}$ in which the mean post-operative mobilization for TLH was $2.7 \pm 0.7$ days versus $3.3 \pm 0.6$ days for TAH group.

Hospital stay is a matter of concern for every patient and their family. Longer hospital stay is usually associated with financial burden, psychologiacl stress. The mean hospital stay of patients in TLH group was significantly shorter when compared to TAH group $(7.6 \pm 1.9$ days versus $10.1 \pm 2.1$ days) which was statistically significant. $(p<0.001)$. This finding is comparable to study by Cracken et $\mathrm{al}^{3}$ done among 135 patients, in which the hospital stay for laparoscopic hysterectomy was significantly shorter than for abdominal hysterectomy with 6.1 days and 8.3 days respectively. Similarly in another study by Frigerio et $\mathrm{l}^{15}$ patients in group TAH had significantly shorter operating time but with longer hospital stay with the mean of 8.5 days in TAH group and 4 days in TLH group.

\section{CONCLUSIONS}

Laparoscopic hyserectomy is an effective alternative to abdominal hysterectomy with the advantage of less intraoperative blood loss, fast recovery and short hospital stay.

\section{DISCLOSURE}

The authors report no conflicts of interest in this work.

No violation of human rights and safety.

Funding: Nil

\section{REFERENCES}

1. Weber AM, Lee JC. Use of alternative technique of hysterectomy in Ohio, 1988-1994. New Eng J Med. 1996; 335(7): 483-9.

2. Mazona R, Busaca M, Zupi E, Garces N, Catalono GF Laparoscopically assisted vaginal hysterectomy verses total abdominal hysterectomy: a prospective, randomized, multicenter study. Am J Obstet Gynecol. 1999;180(1):2705 .

3. Cracken G Mc, Hunter D, Morgan D, Price H. Comparison of laparoscopic -assisted vaginal hysterectomy, total abdominal hysterectomy and vaginal hysterectomy. Ulster Med J. 2006;75(1):54-8.

4. Garry R, Fountain J, Brown J, Mavca A, Mason S, Sulpher M. Evaluate hysterectomy trial: a multicenter randomized trial comparing abdominal, vaginal and laparoscopic methods of hysterectomy. Health Technol Assess. 2004;8 (26):1-154

5. Makinen J, Johansson J, Tomas C, Tomas E, Heinonen PK, Laatikainen T. Morbidity of 10110 hysterectomies by type of approach. Hum Reprod. 2001; 16(7):1473-78.

6. Wingo PA, Huego CM, Rubin GL, Dry HW, Peterson HS. The mortality risk associated with hysterectomy. Am J Obstet Gynaecol. 1995;152:803-08

7. Suttton C. Hysterectomy: a historical operative. Clin Obste Gynaecol. 1997; 11(1):1-22.

8. Michel C, Gerald M, Charles C, Arnaud W, Jean LP, Maurice AB. Laparoscopic hysterectomy. Surg Endosc. 1993;7(10):42-5.

9. Silva-Filto AL, Werneck RA, Magalhaes RS, Belo AV, Triginelli SA. Abdominal versus vaginal hysterectomy: a comparative study of the postoperative quality of life and satisfactions. Arch Gynecol Obstet. 2006;74 (1):21-4.

10. Bernubi GI. History of hysterectomy. J Fla Med Assoc. 1988; 75(8):533-8.

11. John AR, Howard WJ, editors. Telinde's Operative Gynecology. 10th edn. Philadelphia: Lippincott Williams and Wilkins; 2003.

12. Perino A, Cucinella G, Venezia R, Castelli A, Cittadini E. Total laparoscopic hysterectomy versus total abdominal hysterectomy: an assessment of the learning curve in a prospective randomized study. Hum Reprod. 1999;14(12): 2966-99.

13. Loh FH, Koa RC. Laparoscopic hysterectomy versus abdominal hysterectomy: a controlled study of clinical and functional outcomes. Singapore Med J. 2002; 43(8): 403-7.

14. Katherine A, O’Hanlan MD, Gloria SH, Anne-Caroline G Suzanne L, Mirjam L. Total laparoscopic hysterectomy versus total abdominal hysterectomy: cohort review of patients with uterine neoplasia. JSLS. 2005;9(13):277-86.

15. Frigerio L, Gallo A, Ghezzi F, Trezzi G, Lussana M, Franch M. Laparoscopic- assisted hysterectomy versus abdominal hysterectomy in endometrial cancer. Int J Gynecol Obstet. 2006;93(3):209-13 